Research paper

\title{
Prediction of the minimum fluidization velocity of particles of sugarcane bagasse
}

\author{
Nestor Proenza Pérez ${ }^{\mathrm{a}, \mathrm{c}, *}$, Daniel Travieso Pedroso ${ }^{\mathrm{b}}$, Einara Blanco Machin ${ }^{\mathrm{c}}$, \\ Julio Santana Antunes ${ }^{\mathrm{c}}$, Ricardo Alan Verdú Ramos ${ }^{\mathrm{d}}$, Jose Luz Silveira ${ }^{\mathrm{c}}$

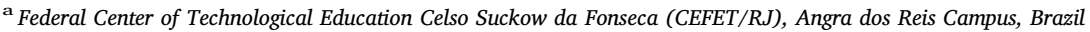 \\ b Technological Development Unit-UDT, University of Concepcion, Coronel, Chile \\ ${ }^{\mathrm{c}}$ São Paulo State University, Faculty of Engineering of Guaratinguetá, Energy Department, Energetic Optimization Systems Laboratory (LOSE,) and Bioenergy Research \\ Institute (IPBEN-UNESP), Brazil \\ ${ }^{\mathrm{d}}$ São Paulo State University, Faculty of Engineering of Ilha Solteira, Energy Department, Bioenergy Research Institute (IPBEN-UNESP), Brazil
}

A R T I C L E I N F O

\section{Keywords:}

Sugar cane bagasse

Fluidization

Minimum fluidization velocity

Fluidized bed

\begin{abstract}
A B S T R A C T
This study refers to an experimental analysis of the fluid-dynamics of particles of sugarcane bagasse in a fluidization column with an internal diameter of $190 \mathrm{~mm}$, which determined the minimum fluidization velocity of the particles with different characteristic diameters $(O<d p<9.5 \mathrm{~mm})$, using air as fluidization means. The results have shown that the minimum fluidization velocity has a tendency to increase as the diameter of the particle increases. However, in a certain range of diameter $(0.88 \mathrm{~mm}<d p<9.5 \mathrm{~mm})$, where the particles have a high aspect ratio (length/diameter), it has not been possible to fluidize them. High superficial air velocities have been used, mainly due to the strong trend to interlace and to develop high adhesion forces in this type of particles, as well as the high porosity that is displayed. Based on the experimental results, two new models have been developed in order to determine the minimum fluidization velocity and the complete fluidization velocity of the sugarcane bagasse with diameters that range from 0.075 to $0.445 \mathrm{~mm}$. The comparisons have been made by using correlations from the literature for the determination of the minimum fluidization velocity, and the experimental results have shown that the new suggested correlations finely predict this parameter, with a maximum error range of $6 \%$, respecting the experimental values.
\end{abstract}

\section{Introduction}

The minimum fluidization velocity is one of the most important parameters that define the fluid-dynamic characteristics of a fluidized bed [1]. Not only does this parameter quantitatively indicate the drag force that is required for the suspension of a solid in the gaseous phase, it also constitutes a reference for evaluating the intensity of the fluidization regime when using high velocities [2].

Therefore, a precise determination of this parameter has vital importance for the fluidization behavior, which is one of the most important factors that influence the combustion and gasification efficiencies [3], and the correct design and operation of fluid-bed equipment [4] [5].

So far, many equations have been obtained in order to calculate this variable for different materials, including steel balls [6], dolomite [7], coal, limestone, iron ore [8], glass beads [9], and others [10], each one with a different particle size distribution and a well-known manner.

A study to determine the minimum fluidization velocity involving wood particles, corresponding to Group C from Geldart classification, has been reported by Reina et al. [1]. By comparing experimental results with correlations reported in the literature by Refs. [6] and [11], these authors conclude that there is not much coincidence between the calculated values in regards to the experimental results, especially in the second correlation., coinciding with the study by Lippens and Mulder [12], where it is suggested that this equation provides poor results when it is used for particles with an sphericity between 0.1 and 0.5. Abdullah et al. [13] report a theoretical and experimental study using biomass residues, such as rice husk, peanut shells, sawdust, coconut shells, and palm fibers, as well as coal and bottom ash, by using the small cold-flow chamber and the pressure drop method for determining the minimum fluidization velocity. Particles from Group B from Geldart classification (coconut shells, sawdust, peanut shells, coal, and bottom ash) have shown a good fluidization, while particles from Group D (rice husks) and A (palm fibers) have had a poor fluidization. The results obtained have been compared to the empirical equation by Leva [14], which has shown significant differences, except for the

\footnotetext{
* Corresponding author. Federal Center of Technological Education Celso Suckow da Fonseca (CEFET/RJ), Angra dos Reis Campus, Brazil.

E-mail address: nestor.perez@cefet-rj.br (N.P. Pérez).
} 


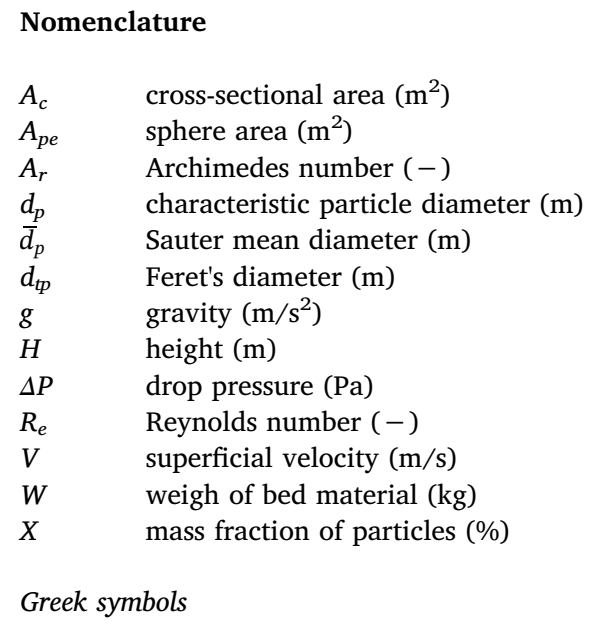

$\begin{array}{ll}P & \text { density }\left(\mathrm{kg} / \mathrm{m}^{3}\right) \\ \Phi & \text { roundness (-) } \\ \mu & \text { viscosity (Pa.s) }\end{array}$

Subscript

$\begin{array}{ll}\text { bulk } & \text { bulk } \\ c f & \text { complete fluidization } \\ e & \text { experimental } \\ f & \text { fixed bed } \\ g & \text { gas } \\ i & \text { each parameter } \\ m f & \text { minimum fluidization } \\ p & \text { particle } \\ r & \text { real or skeletal } \\ s & \text { solid } \\ t & \text { theoretical }\end{array}$

prediction made from rice hulls, which has shown similar values to those from the experimentation stage.

A proposal of a new correlation to determine the minimum fluidization velocity of particles of walnut shell and corn cob is reported by Paudel and Feng [15]. The results have been compared to reported studies by other authors [13], showing that the model has a good behavior when it is used in these types of biomass.

The disagreements between the values predicted by existing correlations applied to biomass particles show the necessity of further information and studies in order to reveal the fluid-dynamic behavior of these types of particles. Several studies have been made by using different types of biomass, but no work has been reported on the fluidization characteristics using sugarcane bagasse. Thus, the aim of this study is to determine the minimum and complete fluidization velocity of particles of sugarcane bagasse, aimed at examining the effect of the particle diameter, density, and form in this parameter.

\section{Materials and methods}

\subsection{Material preparation and properties}

A sample of approximately $150 \mathrm{~kg}$ of sugarcane bagasse from the mills in the central region of São Paulo and from the Brazilian Northeast has been collected. The collected bagasse was composed by mixtures of different varieties of sugarcane, such as RB867515, SP81-3250, RB855453, SP79-1049, SP 91-1049, which are the most used varieties in Brazil and, mainly, in those regions [16]. This bagasse comes from different geographic locations, soil types, harvest time, weather conditions, and harvesting procedures (manual or mechanized ones).

The juice extraction and the bagasse production process is similar to the one reported by Lobo et al. [17]. The process consists of a washing system in which the excessive amounts of soil particles are extracted; then, the sugarcane is inserted in a series of systems, using knives, to reduce the size of the stems, and shredders. These systems, then, promote the fiber opening and the formation of a uniform layer of sugarcane, improving the juice extraction. The extraction process is called tandem mill, and it is typically constituted by 4-7 mills. In each one of them, there are 3-5 rollers and radial grooves in the form of " $\mathrm{V}$ ", which serve to crush and remove the cane juice. Generally, the rollers are arranged in a triangle way, so that the fiber fraction of the sugar cane stalks is compressed twice: once by the upper mobile roller and the input fixed roller, and once between the upper roller and the output roller, in order to separate the juice from the pulp. The bagasse is collected at the end of the belt, and is, from this moment on, called bagasse "in natura". In the previously selected material samples, a subsample has been taken. This sub-sample has been divided, and one of its quarters has been dried in an oven, in order to accelerate this process, due to the high humidity the bagasse has (between 48 and 52\% [18] [19]) at the end of the process. The temperature used in the drying was $103 \pm 1{ }^{\circ} \mathrm{C}$ with a natural air circulation, according to ASTM E871 norm [20]. This dried sample has been divided again in four parts and left in an open bag under atmosphere conditions for several days, until there was an equilibrium moisture content, at an environmental temperature of $27{ }^{\circ} \mathrm{C}$, and atmosphere pressure, simulating the natural drying process that takes place in sugar mills or when different drying techniques are used to diminish humidity to a $10-20 \%$ [19]. In this case, the equilibrium humidity experimentally determined for this bagasse sample has been $8.71 \pm 0.4 \%$.

\subsection{Classification of particle size}

The classification of the particles has been performed according to Geldart's criterion [21], based on the density and particle size and using air as a fluidizing agent under environmental conditions.

In order to determine the distribution of particle sizes, a representative sample of $80 \mathrm{~g}$ of bagasse has been fractionated using sieving techniques. The equipment used was a Produtest vibrating machine, model $\mathrm{T}$, with a sieving time of $20 \mathrm{~min}$. A standardized ASTM E828 has been used [22], with eight screens and wholes of 9.5, 4.75, $2.36,1.18,0.59,0.3$ and $0.15 \mathrm{~mm}$ respectively in the bottom. The weight retained on each sieve has been quantified in a DIGIPESO digital electronic balance, model DP-3000, with an accuracy of $0.01 \mathrm{~g}$. The experiment for the determination of the distribution particle sizes has been repeated 270 times so as to obtain a reliable distribution and an adequate amount of bagasse particles from each diameter of screens used, which would later be used in the fluidization experiments. The average value from all experiments has been adopted as the final result.

The Sauter mean diameter is calculated as [23] [24]:

$\bar{d}_{p}=\left[\frac{1}{\sum_{i=1}^{n}\left(\frac{x_{i}}{d_{p, i}}\right)}\right]$

Where:

$d_{p, i}=\left[\frac{\left(x_{i}^{2}+x_{i+1}^{2}\right) \cdot\left(x_{i}+x_{i+1}\right)}{4}\right]^{0,33}$ 


\subsection{Determination of densities}

In order to determine the real density of bagasse, a helium gas pycnometer has been used, model Quantachrome ULTRAPYC 1200e, with an accuracy of $100 \mathrm{~g} / \mathrm{m}^{3}$, which is able to make five replicate measurements, showing the average value obtained, as well as the standard deviation and the variation coefficient. The apparent density or particle density has been determined by the liquid pycnometric technique. The determination of the bulk density has followed the ASTM E873-82 norm [25], in which an electronic laboratory balance (CELTAC Mark) has been used, with an accuracy of $10 \mathrm{mg}$. In Table 1, the results of this analysis are presented.

\subsection{Voidage}

Bed porosity is defined as the relationship between the volume of the spaces and the total volume of the bed, comprised by the volume of particles and the volume of spaces between them, always being $\varepsilon<1$.

$\varepsilon=\frac{\text { voidage volume }}{\text { volume of particle }+ \text { voids }}$

This parameter is related to the bulk and particle densities by using the following equation:

$\varepsilon=1-\frac{\rho_{\text {bulk }}}{\rho_{p}}$

\subsection{Roundness}

Roundness is a dimensionless parameter, defined as the relation between the sphere area and the projected area of the particle, both with the same volume (Equation (3)).

$\phi=4 \cdot \frac{A_{p e}}{\pi \cdot\left(d_{t p}\right)^{2}}$

For small particles, pith type, the roundness determination has been made by using digital image analysis techniques. In this case, two Zeiss microscopes have been used, as well as a stereo microscope model Stemi 2000, and an optical transmission microscopy model Axioskop 40 , with bright-field illumination and semi-achromatic lens $(2 \lambda, 2 \lambda)$ of $2.5 X, 5.0 X, 20 X$, and the ImageJ software, which makes it possible to fit into an ellipse the binary image projected by the particles, based on second order central moments [26]. For the biggest particles, the determination of this parameter has been carried out according to Heywood and Bernhardt's description [27] [28]; for fibers such as particles, an electronic digital caliper is used, as well as an electronic digital thickness gage, both with a resolution of $0.01 \mathrm{~mm}$.

\subsection{Theoretical analysis}

The pressure drop of a fixed bed is defined by Pavlov et al. [29] as: $\Delta P_{l}=\frac{W}{A_{c}}=$ const

The pressure drop of a fixed bed with length $(L)$, for non-spherical particles with an average diameter $\left(d_{p}\right)$, is given by Ergun [30] as:

$\frac{\Delta P_{l}}{H_{f}}=\frac{150\left(1-\varepsilon_{f}\right)^{2}}{\varepsilon_{f}^{3}} \cdot \frac{\mu_{f} \cdot \mathrm{V}}{\left(\phi \cdot d_{p}\right)^{2}}+\frac{1,75\left(1-\varepsilon_{f}\right)}{\varepsilon_{f}^{3}} \cdot \frac{\left(\rho_{g} \cdot \mathrm{V}\right)^{2}}{\left(\phi \cdot d_{p}\right)}$

When the pressure drop is equal to the weight of the particles per unit area contained in the bed, it starts to expand under these conditions:

$\Delta P_{l}=H_{m f} \cdot\left(1-\varepsilon_{m f}\right) \cdot\left(\rho_{s}-\rho_{g}\right) \cdot g$

By making an arrangement in equations (6) and (7) and multiplying both sides by. $\frac{d_{p}^{3} \cdot \rho_{g}}{\mu_{g}^{2} \cdot\left(1-\varepsilon_{m f}\right)}$

A correlation expressed in terms of dimensionless quantity, known as Archimedes number (Ar) [15], is obtained (some authors have called this term as Galileo number) [6] [31], as well as Reynolds' minimum fluidization number $\left(R e_{m f}\right)$ :

$A_{r}=\frac{150\left(1-\varepsilon_{m f}\right)}{\phi^{2} \varepsilon_{m f}^{3}} \cdot R e_{m f}+\frac{1,75}{\phi \varepsilon_{m f}^{3}} \cdot R e_{m f}^{2}$

Where:

$A_{r}=\frac{d_{p}^{3} \cdot \rho_{g} \cdot\left(\rho_{s}-\rho_{g}\right) \cdot g}{\mu_{f}^{2}}$

$R e_{m f}=\frac{d_{p} \cdot V_{m f} \cdot \rho_{g}}{\mu_{g}^{2}}$

This Ergun equation requires the determination of sphericity and porosity of minimum fluidization parameters, which are very difficult to determine experimentally; therefore Wen and Yu [6] have proposed a simplified form for this equation as it follows:

$0=1650 \cdot R e_{m f}+24.5 \cdot R e_{m f}^{2}-A_{r}$

or

$R e_{m f}=\left(33.7^{2}+0.0408 A_{r}\right)^{0.5}-33.7$

Other researchers have developed their own correlation to determine the minimum fluidization velocity under experimental conditions, being the most known, for different types of biomass among many others, reported in Ref. [32], and shown in Table 2:

\subsection{Experimental installation}

Fig. 1 shows a schematic representation of the experimental installation used in the experiments. The fluidized bed consists of an acrylic column (1), with a thickness of $5 \mathrm{~mm}$, an internal diameter of $190 \mathrm{~mm}$, and a total height of $2.5 \mathrm{~m}$. Regarding the air distributor plate, three sections (two of $1 \mathrm{~m}$ and one of $0.5 \mathrm{~m}$ ) are coupled, forming the dense bed region and the freeboard. In this case, both zones have the same diameter. The installation uses a nozzle-type gas distributor (2) with 33 tuyeres of $0.012 \mathrm{~m}$ of diameter and a triangular arrangement with a $20 \mathrm{~mm}$ pitch. Each pipe has four holes with $2 \mathrm{~mm}$ of diameter each, inclined in $45^{\circ}$ in the cross section. The air has been injected through a radial blower (3). There have been made four pressure taps (4) in the fluidization column, located in the right wall: one was in the gas chamber, below the air distributor plate, and the others were located along the column up to a height of $2.55 \mathrm{~m}$. The static pressure drop across the bed has been measured by using U-tube manometers (5). The heights of fixed and expanded bed have been measured with the aid of a millimeter-sized scale, fixed to the wall of the column.

The superficial air velocity inside the column has been measured with a hot wire anemometer, from Instrutherm, model TAFR-190 (6) with a measuring range of $0-25 \mathrm{~m} / \mathrm{s}$ and a resolution of $0.01 \mathrm{~m} / \mathrm{s}$. A

Table 1

Principal characteristics of particles of sugar cane bagasse.

\begin{tabular}{lllllll}
\hline $\begin{array}{l}\text { diameter } \\
(\mathrm{mm})\end{array}$ & $\begin{array}{l}\rho_{\text {bulk }} \\
\left(\mathrm{kg} / \mathrm{m}^{3}\right)\end{array}$ & $\begin{array}{l}\rho_{p} \\
\left(\mathrm{~kg} / \mathrm{m}^{3}\right)\end{array}$ & $\begin{array}{l}\rho_{r} \\
\left(\mathrm{~kg} / \mathrm{m}^{3}\right)\end{array}$ & $\begin{array}{l}\text { Voidage } \\
(\varepsilon)\end{array}$ & $\begin{array}{l}\text { Roundness } \\
(\phi)\end{array}$ & $\begin{array}{l}\text { Geldart [21] } \\
\text { Classification }\end{array}$ \\
\hline 9.5 & 66.3 & 465.9 & 1389.5 & 0.664 & 0.27 & $\mathrm{D}$ \\
7.125 & 74.6 & 470.6 & 1401.9 & 0.664 & 0.28 & $\mathrm{D}$ \\
3.555 & 77.9 & 478.6 & 1420.8 & 0.663 & 0.32 & $\mathrm{~B}$ \\
1.77 & 79.3 & 483.3 & 1476.1 & 0.672 & 0.28 & $\mathrm{~B}$ \\
0.885 & 82.9 & 520.0 & 1542.2 & 0.674 & 0.30 & $\mathrm{~A}$ \\
0.445 & 93.1 & 560.6 & 1802.9 & 0.711 & 0.34 & $\mathrm{~A}$ \\
0.225 & 107.0 & 605.2 & 1951.7 & 0.712 & 0.54 & $\mathrm{~A}$ \\
0.075 & 147.8 & 484.6 & 2221.1 & 0.727 & 0.55 & $\mathrm{~A}$ \\
\hline
\end{tabular}


Table 2

Correlation to determine the minimum fluidization velocity.

\begin{tabular}{|c|c|c|}
\hline Reference & Correlation & Particle type \\
\hline Reina et al. [1] & $R e_{m f}=\left(48^{2}+0.045 A_{r}\right)^{0.5}-48$ & $\begin{array}{l}\text { different types } \\
\text { of woods }\end{array}$ \\
\hline Paudel e Feng [15] & $R e_{m f}=\left(30.28^{2}+0.108 A_{r}\right)^{0.5}-30.28$ & $\begin{array}{l}\text { walnuts shell, } \\
\text { corn stalk }\end{array}$ \\
\hline $\begin{array}{l}\text { Kozanoglu et al. } \\
\begin{array}{l}{[33] \phi>0,8} \\
0,5<\phi \leq 0,8 \\
\text { both types }\end{array}\end{array}$ & $\begin{array}{l}R e_{m f}=\left(36.8^{2}+0.065 A_{r}\right)^{0.5}-36.8 \\
R e_{m f}=\left(33.6^{2}+0.0598 A_{r}\right)^{0.5}-33.6 \\
R e_{m f}=\left(30.3^{2}+0.0546 A_{r}\right)^{0.5}-30.3\end{array}$ & $\begin{array}{l}\text { black pepper, } \\
\text { millet, } \\
\text { munition } \\
\text { paste, corn, } \\
\text { turf seeds, and } \\
\text { others. }\end{array}$ \\
\hline Babu et al. [8] & $R e_{m f}=\left(25.3^{2}+0.0651 A_{r}\right)^{0.5}-25.3$ & $\begin{array}{l}\text { coal, } \\
\text { limestone, } \\
\text { iron ore }\end{array}$ \\
\hline
\end{tabular}

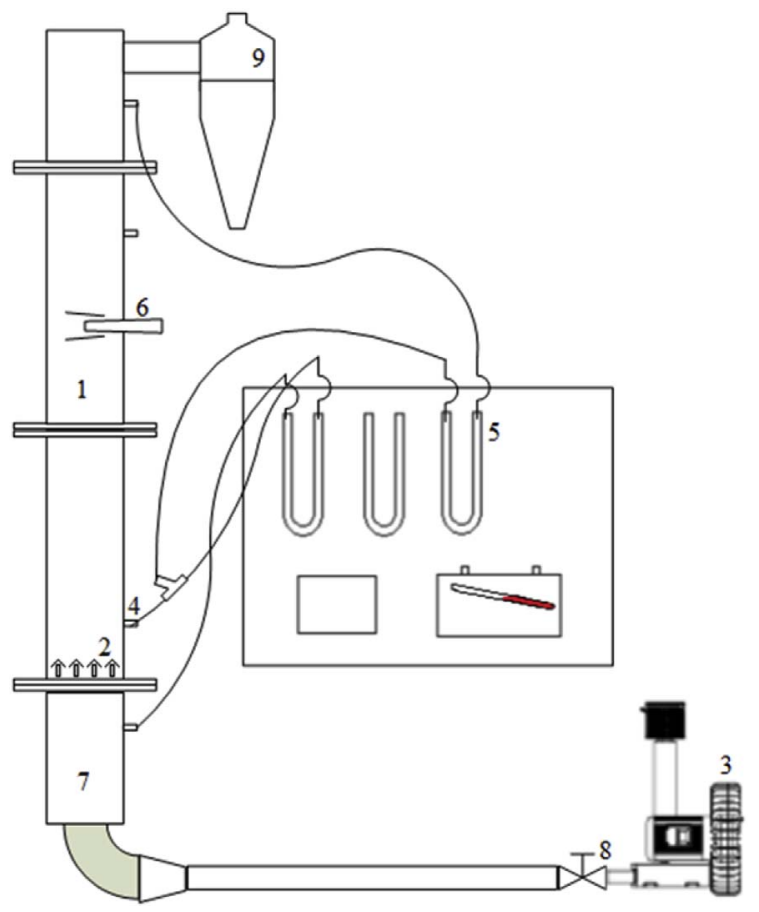

Fig. 1. Schematic diagram of the fluidized bed system.

globe valve (8) installed in the blower output, with an angular graduate aperture, makes it possible to regulate the flow injected precisely into the bed. At the exit of the column a tangential cyclonic separator (9) has been installed to recover the particles that may be elutriated from the bed during the tests.

\subsection{Procedure}

The experiments have been made with a static bed height of $200 \mathrm{~mm}$. Particles of sugar cane bagasse of each size, determined in the sieve analysis, have been introduced through the top of the column in order to reach this height. The minimum fluidization velocity has been determined by the pressure drop method, in which the corresponding value of the $V_{m f}$ is obtained from the intersection of the slope curve, which corresponds to the initial velocity of the air under the fixed bed condition, with the horizontal line indicating the constant pressure drop through the bed, similar to most of previous investigations [5] and [13]. The complete fluidization velocity has been determined based on visual observations that the superficial air velocity in the entire bed started fluidizing vigorously.
The air injection has been gradually controlling the input flow through the angular control valve (for each opening interval there is a correspondent velocity value), the pressure drop data recorded in each case on the U-manometers have been scored. All the experiments have been conducted under room temperature and pressure, with the carrying out of three experimental runs for each particle diameter, considering the average of the obtained values. All the experiments have been analyzed qualitatively and quantitatively, evaluating parameters as total pressure drop through the bed, the bed expansion, and the elutriation velocity of the particles.

There have also been visual observations and images have been recorded with a digital camera. The experimental results have been compared to the predictions of the correlations previously reported in the literature. The comparison criteria used to validate the results has been the Relative Error $(R E)$, defined as:

$R E=\frac{\left|V_{m f e}-V_{m f t}\right|}{V_{m f e}} \cdot 100$

\section{Results and discussion}

The results of the sieve analysis are shown in Table 3. It is possible to see that about $41 \%$ of the total sample is made up by particles with diameters between 0.885 and $9.5 \mathrm{~mm}$, while about $35.4 \%$ is made up by diameters between 0.225 and $0.445 \mathrm{~mm}$. The mass of particles in the lower end of the series of sieves represents $6 \%$ of the total analyzed mass. The characteristic average diameter determined experimentally for sugarcane bagasse "in nature" has been $0.722 \pm 0.08 \mathrm{~mm}$. According to the fraction values in a retained mass, it can be said that the sample has a normal distribution, a contrary result to what has been reported by Polanco et al. [19], using different bagasse samples, where the distribution has shown an almost flat behavior. A possible reason for these differences can be the different methods used to obtain each of the samples in each case. In the study by Polanco et al. [19], the bagasse sample is obtained from different factories, where heaps of bagasse have been stored in an open-air space for a period of time between 1 and 3 years. It is known that the distribution of the size of the bagasse particles can be affected by different factors, such as: the sugarcane varieties used, the system used to extract juice, the type of soil, the weather conditions, the harvest time, and the sampling techniques. The long storage time in an open-air space can favor the emerging of natural segregation, due to the differences in particles' size and density, with the smallest particles as the ones tending to concentrate in the middle and lower part of the heap [34].

Therefore, both studies show coincidences in the value of the average diameter obtained from the bagasse, showing values between 0.7 and $1.3 \mathrm{~mm}$, which are similar to the ones reported by Gabra et al. [35] and De Filippis et al. [36], in which most of the sugarcane bagasse particle concentraiton has been retained in the screens, with diameters

Table 3

Results of Sieve' analysis.

\begin{tabular}{lllllll}
\hline Serie Tyler & $\begin{array}{l}\text { Diameter } \\
\text { range } \\
(\mathrm{mm})\end{array}$ & $\mathrm{d}_{\mathrm{pi}}(\mathrm{mm})$ & $\begin{array}{l}\text { Weight } \\
\text { collected } \\
(\mathrm{g})\end{array}$ & $\begin{array}{l}\text { Weight } \\
\text { fraction } \\
X_{i}\end{array}$ & $\begin{array}{l}\text { Mass } \\
\text { fraction } \\
\text { retained } \\
(\%)\end{array}$ & $\begin{array}{l}\text { Mean } \\
\text { diameter } \\
(\mathrm{mm})\end{array}$ \\
\hline 0.37 in & $9.5-4.75$ & 7.125 & 10.359 & 0.07440 & 12.95 & 0.7221 \\
4 & $4.75-2.36$ & 3.555 & 4.407 & 0.05254 & 5.51 & \\
8 & $2.36-1.18$ & 1.77 & 8.610 & 0.00951 & 10.76 & \\
16 & $1.18-0.59$ & 0.885 & 9.371 & 0.09043 & 11.71 & \\
28 & $0.59-0.3$ & 0.445 & 16.605 & 0.00350 & 20.76 & \\
48 & $0.3-0.15$ & 0.225 & 16.325 & 0.08146 & 20.41 & \\
100 & $0.15-$ & 0.075 & 9.808 & 0.06616 & 12.26 & \\
& $<0.15$ & & & & & \\
bottom & 0 & & 4.515 & 0.07440 & 5.64 & \\
total & & & 80 & & 100 & \\
\hline
\end{tabular}


between $0.25-1.0 \mathrm{~mm}$ and $0.5-1.0 \mathrm{~mm}$, respectively.

In the range of diameters between 0.88 and $9.5 \mathrm{~mm}$, a high aspect ratio has been observed, i.e., the length is bigger than its diameter, which is characteristic of long and fine particles with a higher fiber content, which propitiates a high cohesiveness among them, making the fluidization process virtually impossible to take place.

With particles considered in Group B from Geldart's classification $(\mathrm{dp}=0.88-3.55 \mathrm{~mm}$ ), the air flowed through preferential channels, without any possibility to fluidize the bed. These peculiar features of size and shape in this type of particles, along with the low apparent density presented, have caused an adverse effect on fluidization. This happens mainly due to the tendency to bridge and interlace each other, since that, along with the large interparticle forces (liaison and cohesion forces), they have caused the bed to remain packaged. This process resulted in the formation of nets that have moved up in a plug flow as the superficial air velocity increased up to a certain value. Even using higher air velocities and a certain amount of external energy to break the cohesive forces, it was not enough to break these nets to favor the fluidization. The entire bed moved as a single particle. At a certain point, the particles started reorganizing, joining, and interlacing again, making the fluidization impossible to occur. In Fig. 2, the main problems that prevented the fluidization in this size range are displayed.

Fig. 2 shows the main difficulties presented during the experiments of fluidizing the particles of sugarcane bagasse with characteristic diameters in the range of $0.885-9.5 \mathrm{~mm}$. The main reasons for the fluidization problems are due to the fact that the fluidizing gas produces electrostatic charges and interlacement between the particles that cause the formation of preferential channels and larger interparticle forces. In addition to that, the complex geometric shapes and the large ratio of diameter length in the particles, and the low apparent density may cause the leakage of gas thorough the created spaces (high porosity); an increase in the air flow causes the appearance of a plug flow (slugging), moving the particles in compact blocks. This behavior has been similar to the one reported by Reina et al. [1], who have used wood particles with low density, and to the one found in the study by Zhong et al. [2], who have used particles of corn and cotton stalk. It is also important to highlight that, for the sugarcane bagasse in its natural form $\left(d_{p}=\right.$ $0.722 \mathrm{~mm}$ ), the same problems previously described have been observed in the diameter range of $0.88-9.5 \mathrm{~mm}$, so it has not been possible to fluidize them.

Bagasse particles with characteristic diameters between 0.075 and $0.44 \mathrm{~mm}$, classified by Geldart as Group A, have had a good fluid-dynamic behavior (Fig. 3). In Fig. 4, the determination of the $V_{m f}$ for particles with an average diameter of $0.225 \mathrm{~mm}$ is shown. The $V_{m f}$ value has been determined through the application of the graphical method, in which the slope of the intercept of the fixed bed with the horizontal line of the constant pressure drop is taken as measurement for the $V_{m f}$; in this case, the value has been $0.055 \pm 0.002 \mathrm{~m} / \mathrm{s}$. It is possible to see that the slope 1 , before the $\mathrm{V}_{\mathrm{mf}}=0.055 \mathrm{~m} / \mathrm{s}$, is relatively higher than the second slope, after the $\mathrm{V}_{\mathrm{mf}}=0.055 \mathrm{~m} / \mathrm{s}$. This indicates that the cohesive forces that keep some particles together begin to expand and break when the gas velocity is increased up to a certain value because the impact of the gravitational force is weak, due to the low density of the particles. The bed has easily fluidized with a ratio of $\mathrm{V}_{\mathrm{cf}} / \mathrm{V}_{\mathrm{mf}} \approx 2$. In this case, the value of the complete fluidization velocity has been $0.093 \pm 0.0049 \mathrm{~m} / \mathrm{s}$.

The fluid-dynamic behavior observed differs completely from the behavior shown by more conventional particles, which present a high apparent density and a sphericity near 1 . During the first step in the opening of the valve, it is observed a significant expansion of the bed with the appearance of small preferential channels located in the lower part of the bed near the region of the tuyeres, where the air was injected. An increase in the superficial velocity of air provokes the appearance of the first bubbles, and the channels are expanded up to the surface of the bed, where a very small line is observed with a small quantity of fluidized particles, keeping the rest idle in the bottom of the bed, which is responsible for the trough in the pressure drop curve.

With the increase in the superficial velocity of the gas, the pressure drop in the bed is also increased, causing an enlargement in the flow and in the bubble frequency, which coalesce, growing in size, as they go up the bed and enter the bubbling regime. The bubble has a small size next to the distributor region, but, on its ascending path through the bed, it grows and drags particles in its wake, breaking the interparticle forces (liaison and cohesion forces) through interaction and collisions. The biomass tends to detach itself from the wake created by the upward movement, entering a regime of fluidization when the pressure drop remains almost constant, defining the state where the whole bed is fluidized. This behavior is similar to the one reported by Zhang et al. [5], who have used particles of cotton stalk with a cylindric shape; however, it differs from the study reported by Reina et al. [1], who have used wood particles of different types, where the appearance of a slugging regime tends to arise after the appearance of the preferential channels in the bed; a similar behavior has been reported by Clarke et al. [37] in their study with sawdust particles.

Table 4 shows that the tendency of the minimum fluidization velocities increases along with the average diameter of the particles. This may happen since the bagasse is a biomass with a low density, mainly composed by fibrous particles with a high tendency to bridging; therefore, a diameter increase enlarges the aspect ratio (length/diameter), which has an adverse effect on fluidization, making it necessary to have higher superficial air velocities to fluidize particles with bigger diameters. This fact is in agreement with the results reported by Zhong et al. [2], who have used different biomasses, such as cotton stalk and corn stalk, with physical properties similar to bagasse's.

The results of the prediction of the minimum fluidization velocity using different existent correlations in literature are shown in Table 5 and Fig. 5 respectively. From Table 5, it can be said that the correlation reported by Wen and $\mathrm{Yu}$ [6] and Reina et al. [1] similarly predicts the $V_{m f}$, generally underestimating this parameter in more than $50 \%$ for the whole range of studied particle diameters, not being suitable for particles with sphericity in the range between 0.3 and 0.5 . The correlation of Babu et al. [8] provides the best prediction for particles with a characteristic diameter of $0.445 \mathrm{~mm}$, with a relative error of $7.46 \%$, followed by correlations [15] $28.6 \%$ and [33] $34.7 \%$, respectively. The
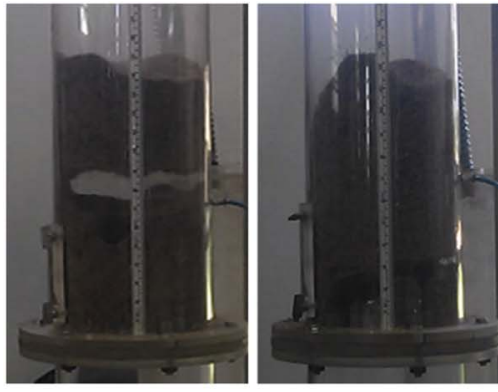

$0.88 \mathrm{~mm}$

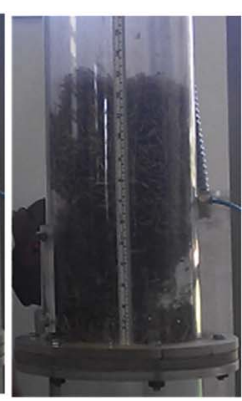

$3.55 \mathrm{~mm}$

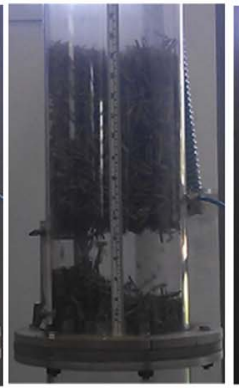

$7.12 \mathrm{~mm}$

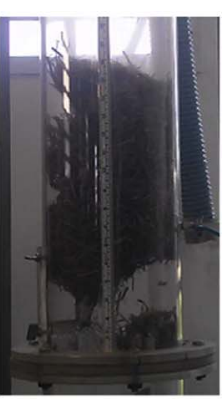

$9.5 \mathrm{~mm}$
Fig. 2. Main problems in fluidization of particles of sugarcane bagasse. 


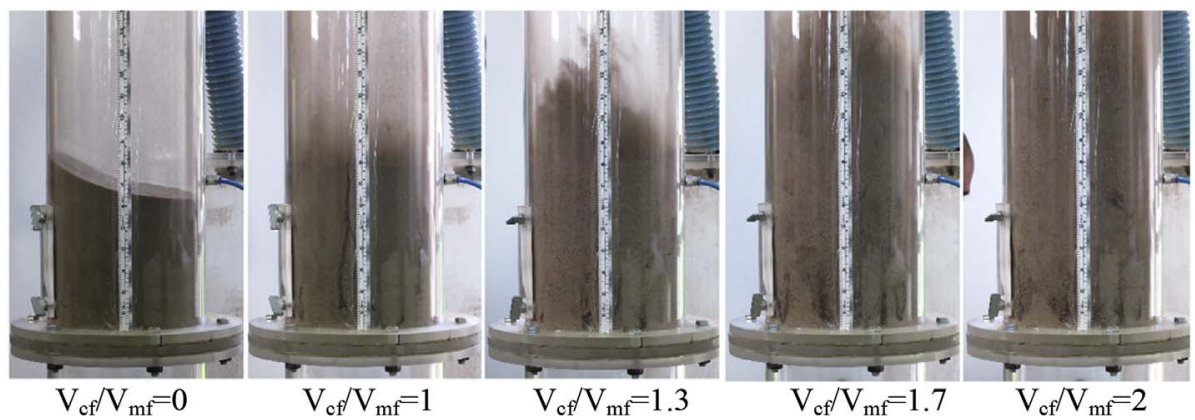

Fig. 3. Fluidization behavior of sugar cane bagasse observed in the experiment.

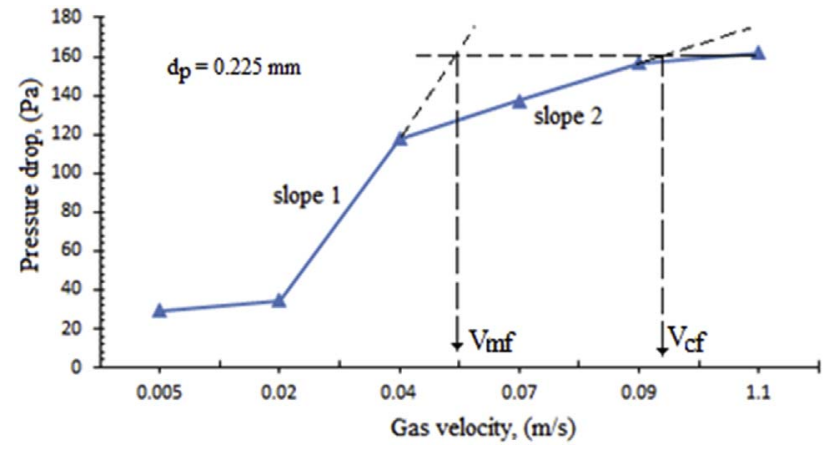

Fig. 4. Pressure drop vs gas velocity for a bed height of $200 \mathrm{~mm}$.

Table 4

Experiment of the minimum and complete fluidization velocities.

\begin{tabular}{llll}
\hline$d_{p}(\mu \mathrm{m})$ & 445 & 225 & 75 \\
\hline$V_{m f}(\mathrm{~cm} / \mathrm{s})$ & $7.2 \pm 0.56$ & $5.5 \pm 0.21$ & $4.5 \pm 0.35$ \\
$V_{f c}(\mathrm{~cm} / \mathrm{s})$ & $16 \pm 0.35$ & $9.3 \pm 0.49$ & $7.0 \pm 0.22$ \\
$R_{e m f}(\exp )$ & 1.99 & 0.77 & 0.21 \\
$A r$ & 1502 & 209 & 8.37 \\
$\Delta P(\exp )(\mathrm{Pa})$ & 145 & 160 & 162 \\
\hline
\end{tabular}

Table 5

Comparation of experimental results of $V_{m f}$ with the prediction of several existing correlations.

\begin{tabular}{llcl}
\hline Author & \multicolumn{2}{l}{$R E\left(V_{m f} \%\right)=f\left(d_{p}(\mathrm{~mm})\right)$} \\
\cline { 2 - 4 } & 0.445 & 0.225 & 0.075 \\
\hline Ergun [30] & +77.4 & +50.9 & -85.5 \\
Wen and Yu [6] & -55.1 & -83.6 & -97.8 \\
Reina et al. [1] & -65.3 & -87.4 & -97.1 \\
Paudel and Feng [15] & +28.6 & -52.0 & -93.1 \\
Kozanoglu et al. [33] & -34.7 & -76.0 & -94.5 \\
Babu et al. [8] & -7.46 & -65.4 & -94.8 \\
\hline
\end{tabular}

$(+)$ percentage above of the experimental value $(-)$ percentage below of the experimental value.

rest of the correlations report errors above $45 \%$ for this size range, with bigger errors insofar as the diameter decreases. None of the correlations attain to predict adequately the minimum fluidization velocity for very small particles $(0.075 \mathrm{~mm})$, being the errors reported above $85 \%$ of the experimental value.

In Fig. 5, the equation offered by Ergun [30] has a tendency to underestimate the $V_{m f}$ value for very small particles $(0.075 \mathrm{~mm})$; nevertheless, for particles with diameters $\geq 0.225 \mathrm{~mm}$, this parameter tends to be overestimated since the huge amount of the errors (77\%) insofar increases the diameter. The behavior shown by the reported equations $[1,6,8,33]$ generally underestimates the $V_{m f}$ value. The tendency of all the equations is very similar since they have all been

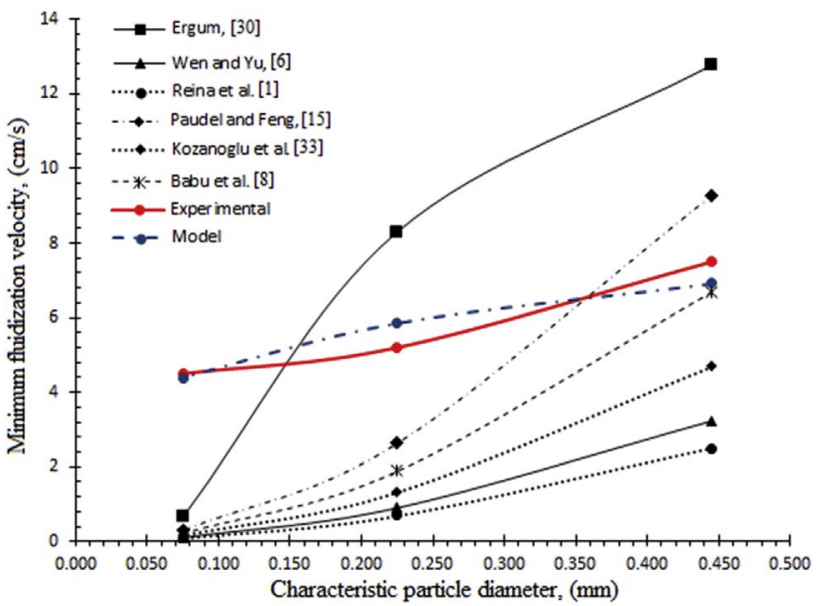

Fig. 5. Theoretical and experimental $V_{m f}$ for sugarcane bagasse.

obtained by modifying Ergun's equation. However, the equation reported by Paudel and Feng [15], also obtained from Ergun's equation, has a tendency to overestimate in $28 \%$ the $V_{m f}$ value for particles with $0.445 \mathrm{~mm}$ of average diameter. Bearing in mind that this equation has been developed specifically for biomass particles (walnut shell, corn stalk), in the case of bagasse, the minimum fluidized velocity cannot be adequately predicted in the size range in which it has been analyzed.

The differences found between calculated values through the correlations existing in literature and through experimental values can be explained by the fact that most of these correlations have been developed from particles of mineral origin, with well-known geometries and specific operation parameters (range of well-defined size, sphericity, and bed porosity), where the effect of interparticle forces that play an important role in fluidization has not been considered. Therefore, the simulated results are not close to reality if these correlations are tested in particles with extreme forms, various sizes, with a high percentage of fine particles and low densities, that promote bridging and interlacement, as in the case of the sugarcane bagasse particles. In the case of correlations specifically developed for biomass particles $[1,15,33]$, differences can be motivated due to the fact that these models have been obtained for a specific diameter range, using biomass particles with properties that are very different from the ones found in sugarcane bagasse, such as density, sphericity, and aspect relation, factors that can directly influence the porosity of the bed and, consequently, interfere with determining the minimum fluidization velocity $\left(V_{m f}\right)$.

With the analysis of the experimental results, it has been possible to develop two mathematical models for the determination of $\left(V_{m f}\right)$ and $\left(V_{f c}\right)$ of the sugarcane bagasse particles, according to equations (14) and (15). These models have been obtained through a series of adjustments by a non-linear regression, which allowed the determination of such parameters as a function of particle diameter, with a correlation factor of $\mathrm{R}^{2}=0.997$ for a minimum fluidization, and $\mathrm{R}^{2}=0.99$ for the complete fluidization respectively (Fig. 6). 


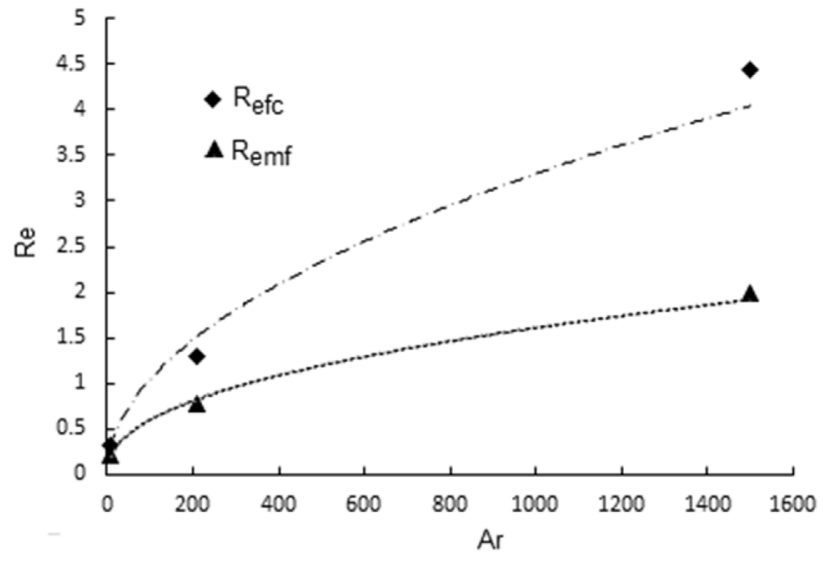

Fig. 6. $R e$ vs $A r$ at incipient $\left(R_{e m f}\right)$ and complete $\left(R_{e f c}\right)$ fluidization.

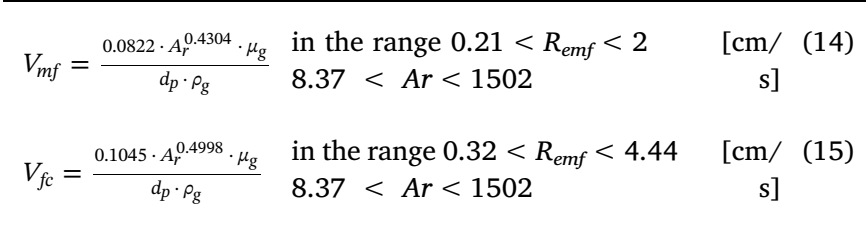

The biomass particles, in most of the cases, show very different physical characteristic from more conventional particles that undergo chemical, mineral, and pharmacological operations in their extreme forms (e.g. long and thin, as with stems or fiber with peculiar shapes, sizes, and densities) [38]. There have been just a few studies carried out to try to understand the fluid-dynamic mechanisms of the biomass particles. Fig. 7 shows the behavior of the fluid-dynamic mechanisms of the biomass particles, which almost follows a linear behavior, increasing $\left(V_{m f}\right)$ as its characteristic diameter increases; in the study by Cardoso et al. [39], who have used sweet sorghum bagasse particles, this behavior has been different, being observed a decreasing $\left(V_{m f}\right)$. In spite of the fact that, in this study, the particles of biomass have been mixed with sand particles, the expected tendency would be an increasing $\left(V_{m f}\right)$ with the growth of the particles' diameter [2] [40]. The authors consider that this behavior is due to the high irregularity, the low aspect ratio, and the sphericity of the particles of this type of biomass.

This makes evident that there is not a well-defined fluidization pattern of biomass particles, which is influenced by the properties of each type of particles used in each case; for this reason, the models developed to determine $\left(V_{m f}\right)$ for certain types of biomass particles do not necessarily have to describe the real fluid-dynamic behavior of other types of particles, since they will strongly depend on the specific properties of these particles and on the operation conditions under which they have been obtained.

The aforementioned proposed models are valid for a narrow particle size range $(O<d p \leq 0.445)$ fluidizing in deep beds $\left(\mathrm{H}_{\mathrm{f}}=200 \mathrm{~mm}\right)$, with a distributor plate with tuyeres. Therefore, if other conditions are to be used, there must be a lot of care. However, if it is to have an idea of the physical magnitude of $V_{m f}$, these models are more convenient than previous correlations reported in the literature, with a maximum relative error of $6 \%$ for $V_{m f}$, and $16 \%$ for $V_{f c}$ respectively, for sugarcane bagasse particles in the already studied diameter range.

In spite of the fact that bagasse "in nature" is not able to be fluidized by itself, due to a wide granulometric distribution and to physical properties with extreme low density and sphericity that it presents, as well as the high tendency to bridge and interlace particles, forming a kind of network with big voids that increase the porosity of the bed, it is possible to use it in fluidized bed systems without the addition of an inert material, diminishing its size or granulometry to an adequate range, as demonstrated in this study.

\section{Conclusions}

Minimum fluidization velocity of sugarcane bagasse in the natural form (in natura) and for different characteristic particles diameter have been determined experimentally.

Experimental data of minimum fluidization velocities showed that particles in the range of diameters between $(0.88 \mathrm{~mm}<d p<9.5 \mathrm{~mm})$, with a long length/diameter relation are not fluidizable. Even by providing a certain amount of external energy to break the cohesive forces present in this type of particles, with extreme forms, (long and thin with low density and sphericity), no fluidization could be achieved. The same result has been obtained for sugarcane bagasse "in natura", composed for all sieve fractions and with mean diameter of $0.722 \mathrm{~mm}$, due to interlacing between the particles that cause the formation of preferential channels and larger interparticle forces, which causes that it is not possible fluidize it also. In the range of fluidizable particles $(0<d p<0.445 \mathrm{~mm})$, a tendency was observed to increase the minimum fluidization velocity with the increase of the characteristic particle diameter.

The bulk density, the sphericity and the porosity are three parameters that influence in the fluidization quality. A high bulk density favors fluidization, meanwhile a high porosity has a negative effect. The using of models reported in the specialized literature for determination of the minimum fluidization velocity, have shown long deviations from the system under study, generally underestimating this parameter. Which corroborates a great dependence to the specific properties of the particles and of the operating conditions in which they models have been obtained. Two new correlations were development to determine $\left(V_{m f}\right)$ and $\left(V_{f c}\right)$, which reasonably describe the behavior of such

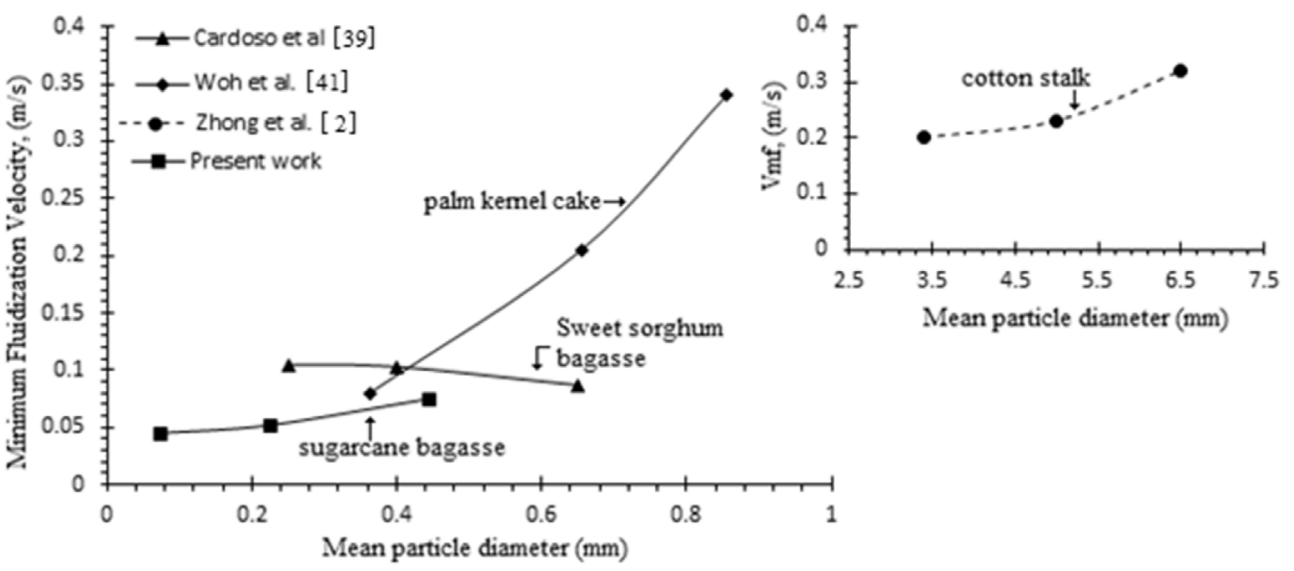

Fig. 7. Fluidization behavior of different biomass particles. 
parameters when they are compared to experimental results, with a maximum relative error of $6 \%$ for $V_{m f}$ and $16 \%$ for $V_{f c}$, respectively.

\section{Acknowledgements}

The authors thank the Coordination of the Improvement of Higher Education Personnel (CAPES) from the Brazilian Ministry of Education (MEC), and the National Council for Scientific and Technological Development (CNPq) (process 150223/2017-0) from the Ministry of Science and Technology (MCT) because of their generous financial support to this research. In addition, the authors highly appreciate Mr. Fernando Araujo for his help and support to carry out the experimental analysis.

\section{References}

[1] J. Reina, E. Velo, L. Puigjaner, Predicting the minimum fluidization velocity of polydisperse mixtures of scrap-wood particles, Powder Technol. 111 (2000) 245-251.

[2] W. Zhong, B. Jin, Y. Zhang, X. Wang, R. Xiao, Fluidization of biomass particles in a gas-solid fluidized bed, Energy \& Fuels 22 (6) (2008) 4170-4176.

[3] E. Natarajan, A. Nordin, A.N. Rao, Overview of combustion and gasification of rice husk in fluidized bed reactors, Biomass Bioenergy 14 (5-6) (1998) 533-546.

[4] M. Hartman, O. Trnka, M. Pohořelý, Minimum and terminal velocities in fluidization of particulate ceramsite at ambient and elevated temperature, Ind. Eng. Chem. Res. 46 (22) (2007) 7260-7266.

[5] Y. Zhang, W. Zhong, B. Jin, Experimental and theoretical study on fluidization of stalk-shaped biomass particle in a fluidized bed, Int. J. Chem. React. Eng. 9 (1) (2011) 1-23.

[6] C.Y. Wen, Y.H. Yu, A generalized method for predicting the minimum fluidization velocity, AIChE J. 12 (3) (1966) 610-612.

[7] S.C. Saxena, G.J. Vogel, The measurement of incipient fluidization velocities in a bed of course dolomite at temperature and pressure, Trans. Inst. Chem. Eng. 55 (1977) 184-189.

[8] S.P. Babu, B. Shah, A. Talwalker, Fluidization correlations for coal gasification materials - minimum fluidization velocity and fluidized bed expansion ratio, Chem. Eng. Prog. Symp. 74 (1978) 176-186.

[9] D.C. Chitester, R.M. Kornosky, Characteristics of fluidization at high pressure, Chem. Eng. Scie 39 (2) (1983) 253-261.

[10] J.R. Grace, Handbook of Multiphase Systems, Hemisphere Pub. Corp, Washington DC, 1986.

[11] A.J. Lucas, J. Arnaldos, L.P. Casal, High temperature incipient fluidization in mono and poly disperse systems, Chem. Eng. Commun. 41 (1986) 121-132.

[12] B.C. Lippens, J. Mulder, Prediction of the minimum fluidization velocity, Powder Technol. 75 (1993) 67-78.

[13] M. Abdullah, Z. Husain, S.Y. Pong, Analysis of cold flow fluidization test results for various biomass fuels, Biomass Bioenergy 24 (2003) 487-494.

[14] M. Leva, Fluidization, McGraw Hill, New York, 1959.

[15] B. Paudel, Z.G. Feng, Prediction of minimum fluidization velocity for binary mixtures of biomass and inert particles, Powder Technol. 237 (2013) 134-140.
[16] C. T, C Centro de tecnologia canavieira, Censo Varietal de Productividade, (2011() [in Portuguese]).

[17] P.C. Lobo, E.F. Jaguaribe, J. Rodrigues, F.A.A. da Rocha, Economics of alternative sugar cane milling options, Appl. Therm. Eng. 27 (8-9) (2007) 1405-1413.

[18] S. Hassuani, M. Leal, I. Macedo, Biomass Power Generation, Sugar Cane Bagasse and Trash, 1st ed., PNUD - Centro de Tecnologia Canavieira (CTC), Piracicaba, 2005.

[19] L.S. Polanco, V. Kochergin, J.F. Alvarez, Fluidized bed superheated steam dryer for Bagasse : effects of particle size distribution, J. Sustain. Bioenergy Syst. 3 (4) (2013) 265-271.

[20] ASTM E871-82, Standard Test Method for Moisture Analysis of Particulate Wood Fuels, Reapproved vol. 2013, (2014).

[21] D. Geldart, Types of gas fluidization, Powder Technol. 7 (1973) 285-292.

[22] ASTM E828-81, Standard test method for designating the size of RDF-3 from its sieve analysis, Reapproved 2004 (2004) 1-8.

[23] O. Kunii, D. Levenspiel, Fluidization Engineering, 2th ed., Heinemann, Butterworth, 1991.

[24] D. Geldart, Gas Fluidization Technology, John Wiley and Sons, 1986.

[25] ASTM E873-82, Standard Test Method for Bulk Density of Densified Particulate Biomass Fuels, Reapproved, 2013 (2014).

[26] B. Rodieck, EllipseFitter class of ImageJ, http://rsb.info.nih.gov/ij/developer/ source/ij/process/EllipseFitter.java.html, (2015) Accessed Febraury.

[27] H. Heywood, Size, shape and size distribution of particulate materials. Course on Particle Technology, (1970) Nordwijk, Netherlands.

[28] B.H.W. Bernhardt, Shape factors of bagasse particles, Proceedings of the South African Sugar Technologists', 1993.

[29] A.A. Pavlov, K.F. Romankov, P.G. Noskov, Problemas y ejemplos para el curso de operaciones básicas y aparatos en Tecnología Química, Moscú, Unión Soviética: Editorial Mir, 1981( [in Spanish]).

[30] S. Ergum, Fluid flow through packed columns, Chem. Eng. Prog. 48 (1952) 89-94.

[31] B. Formisani, R. Girimonte, L. Mancuso, Analysis of the fluidization process of particle beds at high temperature, Chem. Eng. Sci. 53 (5) (1998) 951-961.

[32] S.K. Gupta, V.K. Agarwal, S.N. Singh, V. Seshadri, D. Mills, J. Singh, C. Prakash, Prediction of minimum fluidization velocity for fine tailings materials, Powder Technol. 196 (3) (2009) 263-271.

[33] B.U. Kozanoglu, J. Welti Chanes, D. García Cuautle, J.P. Santos Jean, Hydrodynamics of large particle fluidization in reduced pressure operations: an experimental study, Powder Technol. 125 (1) (2002) 55-60.

[34] R.H. Perry, D.W. Green, Particle size analysis-size reduction and size enlargement, Perry's Chemical Engineers' Handbook, McGraw-Hill, New York, 1997, pp. 5-10.

[35] M. Gabra, E. Pettersson, R. Backman, B. Kjellström, Evaluation of cyclone gasifier performance for gasification of sugar cane residue-Part 2: gasification of cane trash, Biomass Bioenergy 21 (5) (2001) 371-380.

[36] P. De Filippis, C. Borgianni, M. Paolucci, F. Pochetti, Gasification process of Cuban bagasse in a two-stage reactor, Biomass Bioenergy 27 (3) (2004) 247-252.

[37] K.L. Clarke, T. Pugsley, G. a. Hill, Fluidization of moist sawdust in binary particle systems in a gas-solid fluidized bed, Chem. Eng. Sci. 60 (24) (2005) 6909-6918.

[38] H. Cui, J.R. Grace, Fluidization of biomass particles: a review of experimental multiphase flow aspects, Chem. Eng. Sci. 62 (1-2) (2007) 45-55.

[39] T.J.P. Oliveira, C.R. Cardoso, C.H. Ataíde, Bubbling fluidization of biomass and sand binary mixtures: minimum fluidization velocity and particle segregation, Chem. Eng. Process. Process Intensif. 72 (2013) 113-121.

[40] T.R. Rao, J.R. Bheemarasetti, Minimum fluidization velocities of mixtures of biomass and sands, Energy 26 (6) (2001) 633-644. 